\title{
Vittoria Aleotti e Isabella Leonarda, compositoras del barroco italiano
}

Vittoria Aleotti and Isabella Leonarda, composers of the Italian

baroque

Vittoria Aleotti e Isabella Leonarda, compostadores do barroco italiano

\section{Sandra Soler Campo}

Universidad de Barcelona, España

Sandra.soler@ub.edu

https://orcid.org/0000-0002-5560-1415

\section{Resumen}

En el presente artículo se realizará un recorrido histórico del barroco musical Italiano en el que se describirán cuáles eran las posibilidades de algunas mujeres músicas en este periodo así como las posibilidades que tenían para formarse y posteriormente dedicarse a la composición. Así también, se hará mención de la vida y obra de Vittoria Aleotti e Isabella Leonarda, dos de las compositoras más representativas de los siglos XVI y XVII del barroco italiano. Sus obras fueron fundamentalmente vocales y se escribieron para una, dos, tres y/o cuatro voces. Todo ello tuvo lugar en un momento histórico en el que la voz femenina era cada vez más aclamada por el público.

Palabras clave: mujeres; música; compositora; Italia; barroco.

\section{Abstract}

In this article we will make a historical appeal of the Italian musical baroque in which we will describe what were the possibilities of women musicians in this period as well as the possibilities they had to study and later dedicate themselves to composition. It will also be mention the life and works of Vittoria Aleotti and Isabella Leonarda, two of the most representative composers of the 16th and 17th centuries of the Italian 
Baroque. Their works were mainly vocal and were written for one, two, three and/or four voices. All this took place at a historical moment when the public increasingly acclaimed the female voice.

Keywords: women; music; composers; Italy; baroque.

\section{Resumo}

Neste artigo, será realizada uma viagem histórica pelo barroco musical italiano em que serão descritas as possibilidades de algumas músicas nesse período, bem como as possibilidades que tiveram de se formar e depois se dedicar à composição. Além disso, será feita menção à vida e obra de Vittoria Aleotti e Isabella Leonarda, duas das compositoras mais representativas dos séculos XVI e XVII do barroco italiano. Suas obras eram principalmente vocais e escritas para uma, duas, três e / ou quatro vozes. Tudo isso aconteceu em um momento histórico em que a voz feminina foi cada vez mais aclamada pelo público.

Palavras-chave: mulheres; música; compositor; Itália; barroco.

Fecha Recepción: Enero 2020

Fecha Aceptación: Julio 2020

\section{Introducción: el barroco musical italiano}

El Barroco musical fue un periodo que se extendió aproximadamente entre 1600 y 1750, fecha en la que falleció el célebre músico alemán Johan Sebastian Bach. Durante este momento histórico se dieron varias transformaciones sociales, políticas y económicas que repercutieron directamente en las artes. Fue en la península italiana donde nació el estilo Barroco, y desde allí se propagó por el resto del territorio europeo. En general, el arte Barroco se caracterizó por un mayor dramatismo y tensión en las obras de arte.

Uno de los cambios que tuvo lugar durante el barroco y que influyó en la música religiosa fueron las diferentes reformas eclesiásticas. La Contrarreforma reforzó la idea de que el mensaje de la Iglesia era la única y verdadera realidad que conducía a la salvación. Por ello, la institución eclesiástica fue la encargada de controlar la creatividad y expresividad humana. Así, las dos instituciones más importantes, la Iglesia y al Estado, generaron un ambiente de inseguridad en la sociedad. El control de la expresividad humana repercutió directamente en la creación musical. Por ello, a partir de la Contrarreforma, el arte estuvo controlado y a total disposición de la Iglesia. 
Revista Iberoamericana

de las Ciencias Sociales y

Humanísticas

ISSN: $2395-7972$

Durante el Renacimiento surgieron los castrati, niños que habían sido sometidos a una castración para conservar su voz aguda sustituyendo de este modo a la voz femenina. Posteriormente, durante el periodo barroco, aparecieron en escena las figuras femeninas denominadas Primadonna, coincidiendo con el nacimiento de la ópera. Estas mujeres músicas, además de cantantes, eran compositoras. El papel de estas intérpretes de música vocal no dejó indiferente a la audiencia. A lo largo de los siglos XVIII y XIX, la devoción del público hacia ellas se convirtió en un culto a la celebridad. En este periodo, las mujeres que querían dedicarse a la música (bien como compositoras y/o intérpretes) tuvieron que hacer frente a varias dificultades para poder desarrollar su creatividad musical. En general, pudieron hacerlo fundamentalmente en:

- La corte, aquellas mujeres que procedían de familias acomodadas. Únicamente podían hacerlo antes de contraer matrimonio, puesto que una vez casadas debían formar una familia y dedicarse al cuidado de esta.

- Los conventos continuaron siendo centros de producción musical. En ellos se componía música cuya finalidad era su uso en las celebraciones religiosas. En numerosos conventos de la península italiana se han encontrado obras compuestas y firmadas por mujeres. Algunos de los más destacados son los Conventos de Sta. Ágata y el de San Marino de Leano en Pavía; los Conventos de Sta. Caterina, el de Sta. Margarita en Milán; el de Sta. Cristina en Bolonia. El convento de Radegonda (Milán) debió ser un centro de gran importancia por las alusiones que hacen de él viajeros de la época. Además de los conventos, los ospedali (conservatorios) en la Venecia de los siglos XVII y XVIII, se erigen como una de las instituciones más importantes donde las mujeres pudieron estudiar, componer e interpretar música.

- Contraer matrimonio con un músico para poder trabajar junto a él (en ocasiones bajo anonimato).

\section{La música vocal}

El auge de los conjuntos vocales femeninos durante las primeras décadas del período barroco fue un momento importante de la historia de la música, pues el sexo femenino logró alcanzar un destacado reconocimiento por su talento musical. Debido a la creciente popularidad de los conjuntos vocales femeninos que resultaron después del establecimiento del concerto delle donne en 1580, las compositoras en la Italia de 
los siglos XVII y XVIII obtuvieron un mayor acceso a la formación musical. Esta situación dio lugar a que la productividad musical aumentara considerablemente entre las mujeres compositoras, particularmente en el ámbito de la música vocal (Jezic y Wood, 1994).

La fascinación por las voces femeninas, se extendió a una gran diversidad de géneros vocales, pero fue sobretodo en el género operístico en el que alcanzaron la cúspide de la profesión durante las primeras décadas del siglo XVII. Estas mujeres músicas fueron remuneradas y ampliamente aclamadas por sus actuaciones musicales. La asociación que unas décadas después hicieron autores como Monteverdi de las voces agudas con el virtuosismo refleja la importancia de las voces femeninas que se remonta a los concerto delle donne de Ferrara e incluso antes en los espectáculos de la corte donde se contaba con la presencia de castrati. Además de la voz femenina, se confiaba en los castrati para la interpretación de las voces más agudas. Los castrati actuaron por primera vez al coro de la Capilla Sixtina en la década de 1560 y estuvieron considerados como superestrellas de la ópera a finales del siglo XVII (Freitas, 1998).

Cuando Monteverdi comenzó su carrera como músico, las intérpretes femeninas podían actuar con mayor frecuencia en las cortes del norte de Italia y en los espectáculos teatrales patrocinados por la corte, mientras que al final de su carrera pudieron hacerlo ante un gran público interpretando ópera (Treadwell, 2003). Uno de los factores que dificultaron el acceso de las mujeres músicas al gran público fue las diferentes transformaciones faciales que sufría a la hora de interpretar. Es decir, los movimientos, la respiración, y la expresión corporal que requería la interpretación musical. La respiración normal mantenía el calor corporal pero el canto, que requería más energía y liberaba más aire que la respiración, sesgaba este precioso equilibrio haciendo que las mujeres elevaran su propia temperatura corporal (Cusick, 1995).

Al inventarse la imprenta (obra del alemán Johannes Gutenberg que tuvo lugar durante el Renacimiento), se logró un mayor desarrollo y propagación de la cultura en todos sus ámbitos produciéndose una verdadera transformación en política, religión y artes. Este desarrollo culminó durante el Barroco, permitiendo que el saber escrito dejase de ser un patrimonio elitista y se expandiera a gran parte de la sociedad. El ámbito musical no fue una excepción, pues se publicaron composiciones de la época llegándose a difundir composiciones por diferentes territorios. De este modo, cada vez más el mundo era conocedor de cómo se componía en el resto de 
países. Las técnicas de impresión fueron evolucionando de modo que se pudieron realizar tiradas de múltiples ejemplares de libros, composiciones, tratados musicales....Convirtiéndose en una verdadera revolución. Los conventos y monasterios que habían sido centros de creación musical femenina durante los siglos anteriores, continuaron gestando e imprimiendo composiciones nuevas de gran calidad musical (Garvey, 2003). Por tanto, durante el Barroco, el aumento de documentos impresos, fomentó el reconocimiento y la difusión de la creatividad musical de las mujeres. El impulso creativo de las mujeres compositoras barrocas ahora podría imprimirse, interpretarse y ser escuchado en diversos lugares simultáneamente (Rodríguez, 2014).

Las compositoras italianas Vittoria Aleotti e Isabella Leonarda gozaron de una excelente formación musical en el ámbito religioso, pues ambas vivieron y se formaron como músicas en dos conventos italianos como se explicará más adelante. Como consecuencia del auge de la música vocal, la mayor parte de sus composiciones pertenecen a la música vocal de carácter y contenido religioso. Otro punto en común que tiene Vittoria e Isabella es que ambas nacieron y vivieron en el norte de Italia. La primera en Ferrara y la segunda en Novara. No realizaron grandes viajes ni desplazamientos por Europa, ni siquiera en la misma Italia, cosa que podría haber tenido lugar entre los diferentes conventos de las congregaciones a las que pertenecieron.

En 1620, año en el que fallece Vittoria Aleotti, es justamente cuando nace Isabella Leonarda. La primera, nació y se formó en el Renacimiento tardío e inicios del Barroco musical italiano. Este hecho puede explicar que Isabella publicara un gran número de obras (muchas más que Vittoria), ya que la imprenta y la importancia de querer dejar constancia de las obras por escrito para ser interpretadas en un futuro, fue algo que fue ganando cada vez más relevancia con el trascurso de los años.

Así también, se observa en las composiciones de música instrumental de Isabella que el estilo compositivo sigue la segonda prattica, método posiblemente desconocido por Aleotti. 


\section{Música instrumental}

La emancipación de la música instrumental que había iniciado durante el Renacimiento, culminó en el periodo barroco. En este momento histórico se logró alcanzar un doble estilo en la música instrumental: por una parte un estilo de ejecución y por otra un tipo de composición apropiado para cada tipo de instrumento musical.

El desarrollo de la música instrumental durante el barroco estuvo además definido y condicionado por la perfección en la fabricación de los instrumentos y por las innovaciones de tipo compositivo. Estas últimas estuvieron asociadas a los diferentes planteamientos estético-musicales que surgieron y se desarrollaron durante estos siglos (Bianconi, 1986).

El piano, instrumento inventado por el italiano Bartolomeu Cristofori de Padua, debutó en 1750. El piano fue un factor clave y de gran relevancia en el desarrollo de las mujeres como compositoras e intérpretes, de modo que las familias que podían permitírselo económicamente tenían un piano en el salón de sus hogares que a menudo era tocado por ellas, puesto que un gran número de mujeres fue instruida en la práctica del instrumento. Debido a su estética y posición para hacerlo sonar, pronto se convirtió en el instrumento ideal para ser interpretado por una mujer. Muchas familias adquirieron el instrumento para que sus hijas supieran tocarlo y recibieran una educación musical desde la infancia. Las ilimitadas opciones de dinámica y sonoridad que ofrecía el piano hicieron posible que este llegara a ser el instrumento más popular en toda Europa, llegando a ser uno de los medios gracias al cual la mujer empezó a introducirse en el ámbito de la composición.

\section{Prima prattica y seconda prattica}

Durante las primeras décadas del siglo XVII la música italiana distinguía entre la Prima prattica y la Seconda prattica. La Prima prattica (en italiano, primera práctica) se refiere a la música barroca que seguía el estilo compositivo de Giovanni Pierluigi da Palestrina (1525-1594), o al estilo codificado por Gioseffo Zarlino (1517-1590). Esta música contrastaba con la de la Seconda prattica, la cual seguía los nuevos modelos compositivos. Ambos términos surgieron durante la controversia entre Claudio Monteverdi y el teórico Giovanni Maria Artusi a inicios del siglo XVII en torno a la controversia del uso de la disonancia. A partir de Monteverdi en 
adelante, la música antigua o stile antico, fue equivalente a la renacentista, y la nueva o stile moderno a la barroca.

Las formas musicales que surgieron a inicios del siglo XVII tales como la suite, la sonata, el concierto fueron exponentes del stile moderno. Durante la primera mitad del siglo XVII, estas formas convivieron con géneros musicales surgidos durante el periodo anterior y que por tanto se consideraba que seguían el stile antico. Son, por ejemplo, las formas basadas en la imitación, como, la canzona, el ricercare, el capriccio o la fantasía entre otras. El antiguo estilo no se dejó de utilizar aunque se preservó como un segundo lenguaje fundamentalmente en el repertorio de música sacra.

Componer siguiendo el stilo moderno no era adecuado para las mujeres. Sin embargo, la célebre compositora Leonarda Isabella (de quien se hablará más delante) fue educada en el contrapunto formal utilizándolo en algunas de sus piezas (Bowers and Tick 1986, pp.128). El uso de las armonías de Leonarda propició un amplio espacio a la autora para la creatividad. Aunque sus composiciones tienen elementos de ambos estilos, la mayor parte de su repertorio estuvo más cerca del stilo antico en sus obras vocales sagradas y más cerca del stilo moderno en sus obras instrumentales.

\section{Vittoria Aleotti (1575 - 1620)}

Giovanni Battista Aleotti fue un ingeniero y arquitecto italiano que trabajó para la familia Este de Ferrara. Sus cinco hijas, Raphaela, Vittoria, Beatrice, Cinzia, Camilla y Armanda recibieron formación musical. De todas ellas, Raphaela y Vittoria fueron las compositoras más reconocidas de la familia Aleotti. Su progenitor se aseguró de proporcionar una educación eclesiástica a su hija mayor, Raphaela. Sus estudios musicales fueron realizados a cargo del maestro Alessandro Milleville. En 1593 compuso y publicó el libro de motetes para el conjunto coral del convento de San Vito titualdo Sacrae cantiones: quinque, septem, octo \& decem vocibus decantande. Fue su única publicación y la dedicó al obispo de Ferrara. Estos motetes, una de las primeras obras de la historia impresas compuestas por una mujer, muestran el talento de Raphaela, cuya escritura vocal era clara, usaba una textura simple y una nueva independencia de dos coros que cantan con un estilo declamatorio moderno. Fue también conocida como excelente organista. Durante los años en los que vivió en el convento, se dedicó posiblemente más a la enseñanza y la interpretación que a la composición. 
El convento de San Vito, durante la mayor parte del Renacimiento tardío, ofreció al público interpretaciones de sofisticadas obras musicales. Algunas monjas, además de intérpretes de música vocal, tocaron instrumentos de viento como cornetas, trombones. Hercole Bottrigari, un erudito y músico italiano, publicó una discusión en su obra, Il Desiderio, describiendo a las talentosas mujeres músicas de San Vito, siendo Raphaela probablemente la líder y maestra de muchas de ellas.

Vittoria, la segunda hija de Aleotti, fue en gran parte autodidacta mientras pudo observar a su hermana mayor durante las lecciones particulares de música. Vittoria, que ya tocaba el clavicémbalo a los 4 ó 5 años, estudió con los maestros Milleville y Ercole Pasquini. Vivió en el convento de San Vito durante varios años antes de elegir dedicar su vida a Dios y tomar sus votos a los 14 años de edad. Permaneció en el convento durante cuarenta y nueve años, sirviendo como música, directora de orquesta, teclista y compositora. Esta publicó un madrigal en 1591 titulado Giardino de' musici ferraresi, y un libro de madrigales en 1593 titulado Ghirlanda de madrigali a quattro voce. Además de estas dos obras, las composiciones más conocidas de la autora fueron T'amo mia vita, Io v'amo vito mia; Exurgat Deus; Ego flos campi; Sacrae cantiones: quinque, septem, octo \& decem vocibus decantande. Obras todas ellas de música vocal sacra.

\section{Isabella Leonarda $(1620$ - 1704)}

La familia Leonardi fueron una antigua y prominente familia de Novara. Entre los diferentes miembros hubo importantes funcionarios de la iglesia y de la sociedad civil y caballeros palatinos. El padre de Isabella, quien tenía el título de conde, fue un gran experto en leyes (Carter, 1988).

Isabella estudió composición con Gasparo Casati, maestro de capilla de la catedral de Novara desde 1635 a 1641. Las Ursulinas fueron una orden de enseñanza y el convento llevó el título de Collegio. Probablemente esta fue la institución en la que Isabella recibió algún tipo de educación. Aunque no se menciona que Gasparo fuese el maestro de Isabella, la tradición de incluir la composición de un estudiante en la publicación de su maestro lo hace parecer probable. Así pues, en el Tercer Libro de los Sagrados Conciertos Terzo libro desacri concerti publicado en 1640, se encuentran varias obras dedicadas por el autor Al Reverendo Padre". D. Sebastiano Contarini abbate di Santo Ambrogio Maggiore di Milano, Conte di Campione, Limonta, et Civenna, así como también dos motetes de M. rev. signora Isabella 
Revista Iberoamericana

de las Ciencias Sociales y

Humanísticas

ISSN: $2395-7972$

Leonarda Vergine nella Congregatione di S. Orsola di Novara. Aunque poco se conoce de la labor docente de Isabella, en 1658 se la menciona como profesora de música y madre y secretaria del convento (Carter, 1988). De sus posteriores composiciones publicadas en 1686, 1693, 1695, 1696 y finalmente 1700 puede deducirse que ascendió posiciones en el convento desde la Vicaría Madre hasta Superiora y finalmente Consigliera en 1700.

La mayoría de las monjas que compusieron obras escribieron obras vocales tales como motetes y/o madrigales. No obstante, este no fue el caso de Isabella, quien aunque compuso fundamentalmente música vocal religiosa (escribió también algunas canciones sagradas en solitario con letras en lengua vernácula), compuso además música instrumental al estilo barroco italiano. Se cree que las sonatas Opus 16 son las primeras sonatas instrumentales (para violín y continuo) publicadas por una compositora. Fueron publicadas en 1693, cuando Isabella tenía 73 años. Esta primera edición (como se observa en la imagen 2) es un ejemplo de impresión musical en caracteres móviles en la que las cabezas de las figuras musicales adoptan una forma ovalada. Aunque a veces su lectura musical no sea sencilla, debe tenerse en cuenta que esta era la manera más rápida (aunque suponía un elevado coste) en tiradas relativamente cortas.

Isabella fue una de las más prolíficas compositoras del barroco italiano llegando a publicar más de doscientas obras. Fue una compositora muy apreciada en su ciudad natal, aunque muy poco conocida en el resto de Italia. Sus composiciones publicadas abarcan un período de unos 60 años que comenzó con los diálogos de 1640 y terminó con la voz solista Mottetti de 1700.

\section{Interpretación de las composiciones de Isabella Leonarda y Vittoria Aleotti antes y en la actualidad}

Toda la música que compuso Isabella, incluyendo las sonatas instrumentales fue apropiada para interpretarse en cualquier contexto religioso. No obstante, no se ha investigado todavía si su música se utilizó en pocas o muchas ocasiones. Tampoco sabemos dónde fue interpretada (en caso de haberlo sido). Sin embargo, algunas de sus obras han llegado a la actualidad incompletas.Se supone que en el convento llegaron a interpretarse algunas de sus obras, pues, en ellos la formación musical y interpretación musical formaban parte de cotidianeidad. Este desconocimiento se da también con las piezas compuestas por Vittoria Aleotti. 
En la actualidad, las obras de Isabella Leonarda forman parte de algunos programas de concierto y agrupaciones musicales como por ejemplo el conjunto inglés Cappella Fede, el cual está especializado en música vocal e instrumental secular y sagrada desde 1650 a 1790. Otras agrupaciones como la Bristol Ensemble siguen interpretando obras suyas como por ejemplo la mencionada Sonata Duodecima, la cual se considera es la primera sonata para violín compuesta por una mujer. Esta pieza forma parte de una colección de 12 sonatas, por lo tanto, es la última sonata y la más avanzada harmónicamente la que cierra este ciclo de sonatas para violín y continuo.

Agrupaciones vocales como The Philarmonic Society of Arlington (Massachusetts) interpretan un repertorio conformado única y exclusivamente por composiciones de Vittoria Aleotti, Isabella Loenarda entre otras músicas como Maddalena Casulana, Barbara Strozzi así como también obras de compositoras de siglos posteriores como Fanny Hensel, Clara Schumann, Amy Marcy Cheney Beach, Mabel Wheeler Daniels o Gwyneth Walker entre otras.

\section{Conclusiones}

Durante el barroco italiano, la gran mayoría de piezas no llegaron a imprimirse, puesto que el hecho que las composiciones perduraran en el tiempo no era siempre el objetivo por el cual se componían las obras. A pesar de ello, además de las dos compositoras mencionadas, otras célebres compositoras como la también italiana Bárbara Strozzi vieron publicados ocho volúmenes de sus madrigales.

La vida y obra de Vittoria Aleotti e Isabella Leonarda puede describirse como atípica en un momento histórico en el que las mujeres tenían como objetivo primordial el cuidado de la familia y la realización de las tareas domésticas. A través de su vida y obra, hemos podido conocer sus composiciones, las cuales seguían los estilos compositivos de la época y que cualquiera de sus iguales masculinos podía componer. A pesar de vivir y desarrollarse como músicas en una sociedad patriarcal, la exitosa carrera profesional de estas dos compositoras durante barroco italiano atestigua el acceso cada vez mayor a una mejor formación musical femenina después de 1580 .

A pesar de que se considera que sus algunas de sus obras son de una calidad extraordinaria y que siguieron los métodos compositivos de la época en que vivieron, son escasas el número de obras de estas y otras compositoras las que forman parte de los programas de conciertos de música vocal y/o instrumental barroca. Por ello, 
creemos y reivindicamos la necesidad que se incluyan sus piezas en las programaciones y que sus obras puedan difundirse y ser escuchadas por toda la humanidad.

\section{Futuras líneas de investigación}

Son varias las líneas de investigación que permanecen abiertas en la actualidad y continúan desarrollándose con el objetivo de conocer más sobre la vida y obra de autoras de los diferentes periodos históricos.

Aunque está documentada la biografía de músicas que desarrollaron su carrera artística durante el periodo Barroco, es difícil conocer el número exacto de obras compuestas por el sexo femenino. Lamentablemente tampoco podemos saber cómo sonaban sus obras, puesto que una gran mayoría no llegaron a publicarse y ni siquiera a interpretarse. Por lo tanto, desde el presente siglo XXI, nos queda recordar su aportación al mundo artístico y seguir interpretando sus composiciones y estrenar aquellas que nunca han podido ser escuchadas por un público. Es esta última, la interpretación, una de las futuras líneas de investigación muy interesantes con el doble objetivo de volver a dar vida a estas obras y que el público pueda disfrutar con ellas. 


\section{Referencias}

Bianconi, L. (1986). El siglo xvii en historia de la música vol 5. Madrid: Turner música.

Carter, S. (1988). Isabella leonarda: selected compositions. A-r editions, Inc.

Cusick, S. Raffaella Aleotti. En L. Macy (Ed.), The Groove Music Online. Recuperado de https://www.oxfordmusiconline.com/grovemusic/view/10.1093/gmo/9781561 592630.001.0001/omo-9781561592630-e-0000000518.

Cusick, S. (1999). "On Musical Performances of Gender and Sex.” Audible Traces: Gender, Identity, and Music. Eds. Elaine Barkin and Lydia Hamessley. Zurich and Los Angeles: Carciofoli Verlagshaus, pp. 25-48.

Freitas, R (1998). Un atto d'ingegno: a castrato in the seventeenth century. New haven: Yale university press.

Garvey, B. (2003). The seventeenth century in from convent to concert hall: a guide to women composers, ed. Sylvia Glickman and Martha furman schleifer. Westport: Greenwood.

Jezic, D. y Wood, E. (1994). Women composers: the lost tradition found. New york: the feminist press.

Rodríguez, B. (2004). Del original de imprenta al libro impreso antiguo. Madrid: Ollero y Ramos editores.

Treadwell, N. (2003). Restaging the sirens: musical women in the performance of sixteenth-century Italian theater. University of southern California. 